\title{
Estimating the chance of success of information acquisition for the Norne benchmark case
}

Vinicius Eduardo Botechia ${ }^{1, *}$, Daniel Rodrigues dos Santos $^{1}$, Carlos Eduardo Andrade Barreto ${ }^{2}$, Ana Teresa Ferreira da Silva Gaspar ${ }^{1}$, Susana Margarida da Graça Santos ${ }^{1}$, and Denis José Schiozer ${ }^{1}$

${ }^{1}$ University of Campinas - Center for Petroleum Studies, PO Box 6052, 13083-970 Campinas, SP, Brazil

2 SOLPE - Solutions for Petroleum Science and Engineering, Av. Alan Turing, 345, Room 12, 13083-898 Campinas, SP, Brazil

Received: 26 April 2018 / Accepted: 27 August 2018

\begin{abstract}
A key decision in field management is whether or not to acquire information to either improve project economics or reduce uncertainties. A widely spread technique to quantify the gain of information acquisition is Value of Information (VoI). However, estimating the possible outcomes of future information without the data is a complex task. While traditional VoI estimates are based on a single average value, the Chance of Success (CoS) methodology works as a diagnostic tool, estimating a range of possible outcomes that vary because of reservoir uncertainties. The objective of this work is to estimate the CoS of a $4 \mathrm{D}$ seismic before having the data, applied to a complex real case (Norne field). The objective is to assist the decision of whether, or not, to acquire further data. The methodology comprises the following steps: uncertainty quantification, selection of Representative Models (RMs), estimation of the acquisition period, production strategy optimization and, finally, quantification of the CoS. The estimates use numerical reservoir simulation, economic analysis, and uncertainty evaluation. We performed analyses considering perfect and imperfect information. We aim to verify the increment in economic return when the $4 \mathrm{D}$ data identifies the closest-to-reality reservoir model. While the traditional expected VoI calculation provides only an average value, this methodology has the advantage of considering the increase in the economic return due to reservoir uncertainties, characterized by different RMs. Our results showed that decreased reliability of information affected the decision of which production strategy to select. In our case, information reliability less than $70 \%$ is insufficient to change the perception of the uncertain reservoir and consequently decisions. Furthermore, when the reliability reached around $50 \%$, the information lost value, as the economic return became similar to that of the case without information acquisition.
\end{abstract}

\section{Nomenclature}

4DS

$\mathrm{CoS}$

4D Seismic data

$d$

EMV

EVII Chance of Success

Distance

EVoI Expected Monetary Value

EVPI

Max

Min

$\mathrm{Ng}$

$\mathrm{Np}$

NPV Expected Value of Imperfect Information Expected Value of Information Expected Value of Perfect Information Maximum value of determined indicator Minimum value of determined indicator

NPVwi Net Present Value with information

NPVwoi Net Present Value without information

Number of grid cells

Cumulative oil produced

Net Present Value
$\mathrm{N}_{\mathrm{SCNr}}$

$\mathrm{P} 50$

$P_{\mathrm{c}}$

$P_{\mathrm{p}}$

$P_{\mathrm{r}}$

$P_{\mathrm{RMr}}$

$P_{\mathrm{u}}$

$\mathrm{RF}$

$\mathrm{RM}$

$\mathrm{Sw}_{\mathrm{i}}^{\text {base }}$

* Corresponding author: botechia@cepetro.unicamp.br

Number of scenarios having the lowest distance value $(d)$ with respect to the $\mathrm{RM}_{\mathrm{r}}$ Percentile 50

Current probability

Predicted probability

Reliability probability

Probability of the representative model $r$ Updated probabilities

Oil Recovery Factor

Representative Model

Water saturation of the base model for each grid block $i$

$\mathrm{Sw}_{\mathrm{i}}{ }^{\text {scenario }}$ Water saturation of each scenario for each grid block $i$

$\mathrm{T}_{\mathrm{SCN}} \quad$ Total number of scenarios

VoI Value of Information

VOPI Value Of Perfect Information 
Wp Cumulative water produced

$\triangle \mathrm{NPV}$ Difference between NPVwi and NPVwoi

$\varepsilon \quad$ Water saturation error

$\varepsilon_{\text {norm }} \quad$ Normalized water saturation error

\section{Introduction}

An efficient way to evaluate strategies is fundamental to maximize economic performance of field operation and infrastructure decisions. However, this can be very complex since many decisions are made in scenarios involving high investments and multiple uncertainties. The decision to acquire information can aid the selection of a better strategy, but the costs and benefits must be justified.

A widely used tool to assist decision makers in how to reduce uncertainty before selecting a course of action is Value of Information (VoI) (Schlaifer, 1959; Grayson, 1960; Howard, 1966). A classical definition of VoI is the difference between the expected value with information and the expected value without information (Coopersmith and Cunningham, 2002). However, Bratvold et al. (2009) state that this is a misconception of $\mathrm{VoI}$, while the concept is true in many cases, for example, under risk neutrality, it is not in general.

The value of gathering new information depends on several factors: degree of uncertainty (the greater the uncertainties, the greater the VoI), representativeness of the information, decision flexibility, the magnitude of future monetary impact on changing decisions, and the reliability of the information (Gerhardt and Haldorsen, 1989; Coopersmith and Cunningham, 2002).

Eidsvik et al. (2015) presented applications of VoI in earth sciences, integrating this topic with spatial modeling. Abellan and Noetinger (2010) proposed an approach that allows quantifying the information contained in measurements in a geoscience context. Recently, the VoI concept is being used in history matching contexts, involving data gathered at different times (Barros et al., 2015, 2016; He et al., 2016; Chen et al., 2017; Hong et al., 2018). Hong et al. (2018) discussed the variability of VoI over ensembles, including Bayesian inference with ensemble Kalman filter (EnKF) (Evensen, 1994).

An important source of information that can add value to an oil field project is $4 \mathrm{D}$ seismic data because it provides a better understanding of the variations of dynamic properties in the reservoir (Davolio and Schiozer, 2018). This type of information has been widely used in model-based approaches, such as reservoir management, production optimization, and history matching techniques (Le Ravalec et al., 2012a, 2012b; Roggero et al., 2012; Tillier et al., 2012).

The presence of uncertainties and the complex interrelationships involved in large development decisions require probabilistic approaches to calculate $\mathrm{VoI}$ (Begg et al., 2002). Decision trees and Bayesian analyses (statistical method to revise probability estimates given new information - Waggoner, 2002) are widely used in the literature to assess VoI (Raiffa, 1968; Waggoner, 2002; Galli et al., 2004; Ballin et al., 2005; Bailey et al., 2011; Santos et al., 2017).
If the information provides perfect knowledge of the state of the world, then it is called perfect information, and $\mathrm{VoI}$ is referred to as Value Of Perfect Information (VOPI) or Expected Value of Perfect Information (EVPI) (Bratvold et al., 2009). However, in practice, information is rarely perfect because of uncertainty. This is imperfect information. In fact, perfect information works as an upper limit for imperfect information (Coopersmith and Cunningham, 2002), and the VoI, in this case, can be also referred to as Expected Value of Imperfect Information (EVII).

Usually, VoI determines the Expected Monetary Value (EMV) of acquiring and analyzing data to reduce uncertainty (Begg et al., 2002). Estimating VoI before data acquisition is complex because of the many possible outcomes and must consider the uncertainties of the reservoir models (Dunn, 1992). In this context, Ferreira and Schiozer (2014) use the term Expected Value of Information (EVoI) when the valuation is made before the data acquisition, and this is the term we use in the text from now on.

Ferreira et al. (2015) claimed that being a weighted average, the EVoI does not reflect the variation in the increase of the expected revenue due to information acquisition. In order to complement the traditional approach, the authors proposed the Chance of Success (CoS) methodology, a diagnostic tool that gives ranges of possible outcomes for the increase in the difference of the Net Present Value (NPV) with (NPVwi) and without information (NPVwoi) considering different scenarios. This allows the estimation of the probability of increased expected revenue to surpass the costs of information acquisition, considering perfect information and a simple synthetic reservoir model.

The idea of this approach is to decide whether the information should be acquired. If the information is acquired, it will inform which the most-likely RM is; hence, we can decide which production strategy should be selected.

\section{Objectives and assumptions}

This work estimates the $\mathrm{CoS}$ of a $4 \mathrm{D}$ seismic project before acquiring 4D seismic data (based on the works of Ferreira and Schiozer, 2014 and Ferreira et al., 2015), applied to the Norne benchmark model, considering perfect and imperfect information. The objective is to identify which Representative Model (RM) is closest to the real model and assess the increment on the economic return.

\section{Methodology}

The proposed CoS methodology is based on the works of Ferreira and Schiozer (2014) and Ferreira et al. (2015), comprising the six steps shown in Figure 1.

\subsection{Uncertainty and risk analyses}

The first step defines the uncertain parameters of the reservoir model. Statistical procedures combine all uncertainties to generate many scenarios (simulation models). A base case is chosen from these models (usually that closest to the percentile P50). 


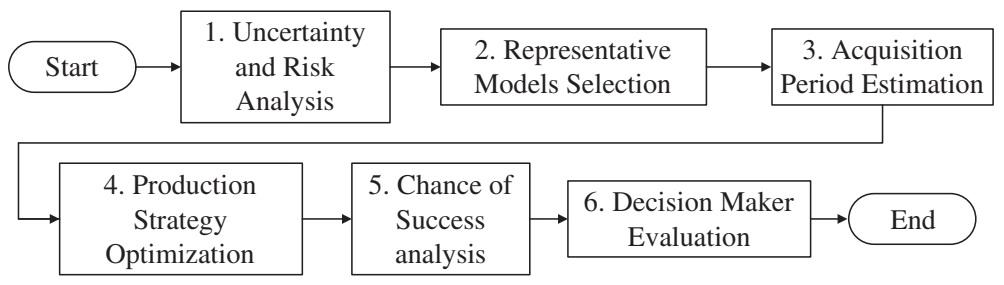

Fig. 1. Methodology to estimate the chance of success of 4D seismic acquisition (adapted from Ferreira and Schiozer, 2014).

We optimize a production strategy for the base case (base production strategy). This strategy is applied to all the other models, the NPV for each model is calculated, and a risk curve (descendent or complementary cumulative distribution function) is plotted.

\subsection{Selection of representative models}

Optimizing the hundreds of models generated in the first step is computationally impractical, so in this step, RMs are selected to reduce the number of models to be optimized (Schiozer et al., 2004; Costa et al., 2008; Marques et al., 2013; Sarma et al., 2013; Shirangi and Durlofsky, 2015; Meira et al., 2016). The RMs represent the variability of the uncertainties (input and output) in a few models. These are then optimized to have different project options, each representing the best decision for different scenarios. We base the selection of representative models on the procedure by Meira et al. (2017), which evaluates the variability of the models on the following parameters: NPV, oil Recovery Factor (RF), cumulative oil (Np), and cumulative water $(\mathrm{Wp})$.

Each RM may have a specific probability of occurrence, which we determine according to Ferreira et al. (2015) equation (1):

$$
P_{\mathrm{RMr}}=\left(\frac{N_{\mathrm{SCNr}}}{T_{\mathrm{SCN}}}\right) \times 100
$$

where $P_{\mathrm{RMr}}$ is the probability of the representative model $r, N_{\mathrm{SCNr}}$ is the number of scenarios with the lowest distance value $(d)$ with respect to the representative model $\mathrm{RMr}$ and $T_{\mathrm{SCN}}$ is the total number of scenarios.

The measure referred to as "distance" $(d)$ is a comparison between the normalized production and economic results of each representative model and is calculated using equation (2):

$$
\begin{aligned}
d_{\mathrm{jr}}= & \frac{\left(\mathrm{Np}_{\mathrm{j}}-\mathrm{Np}_{\mathrm{RMr}}\right)^{2}}{\left(\operatorname{Max}\left(\mathrm{Np}_{\mathrm{j}}\right)-\mathrm{Min}\left(\mathrm{Np}_{\mathrm{j}}\right)\right)^{2}} \\
& +\frac{\left(\mathrm{Wp}_{\mathrm{j}}-\mathrm{Wp}_{\mathrm{RMr}}\right)^{2}}{\left(\operatorname{Max}\left(\mathrm{Wp}_{\mathrm{j}}\right)-\mathrm{Min}\left(\mathrm{Wp}_{\mathrm{j}}\right)\right)^{2}} \\
& +\frac{\left(\mathrm{RF}_{\mathrm{j}}-\mathrm{RF}_{\mathrm{RMr}}\right)^{2}}{\left(\operatorname{Max}\left(\mathrm{RF}_{\mathrm{j}}\right)-\operatorname{Min}\left(\mathrm{RF}_{\mathrm{j}}\right)\right)^{2}} \\
& +\frac{\left(\mathrm{NPV}_{\mathrm{j}}-\mathrm{NPV} \mathrm{RMr}_{\mathrm{r}}\right)^{2}}{\left.\left(\operatorname{Max}\left(\mathrm{NPV}_{\mathrm{j}}\right)-\mathrm{Min}_{\mathrm{NPV}}\right)\right)^{2}}
\end{aligned}
$$

where $d$ is the distance of the normalized production and economic results from the scenario $j$ to the representative model (RMr) under analysis. Max and Min refer to the maximum and minimum values, respectively, obtained for each indicator among all scenarios.

\subsection{Estimation of the acquisition period}

The time for 4D seismic acquisition is best when: (1) only $4 \mathrm{D}$ seismic data can identify that the base model is nonrepresentative of the true earth model, and (2) there is time to make or change decisions (Ferreira et al., 2011).

Thus, the value of $4 \mathrm{D}$ seismic data is affected by the period of acquisition. We evaluate the information from the $4 \mathrm{D}$ seismic data using water saturation maps to consider two points: (1) ensure that the base reservoir model does not represent the true earth model, and (2) anticipate the water breakthrough for producers.

To find the best time to acquire information, we use the methods by Ferreira et al. (2011) and Ferreira and Schiozer (2013), which calculate an error function that represents the mismatch between the simulation scenario and the water saturation maps for the base model (Eq. (3)). The normalized error function is given by equation (4).

$$
\begin{aligned}
\varepsilon & =\sum_{i=1}^{N g}\left(\mathrm{Sw}_{i}^{\text {scenario }}-\mathrm{Sw}_{i}^{\text {base }}\right) \\
\varepsilon_{\text {norm }} & =\frac{\varepsilon}{\operatorname{highest}(\varepsilon)}
\end{aligned}
$$

where $\varepsilon$ is the error, $N \mathrm{~g}$ is the number of grid cells, $\mathrm{Sw}_{i}{ }^{\text {scenario }}$ is the water saturation of a specific scenario for each grid block $i$ and $\mathrm{Sw}_{\mathrm{i}}^{\text {base }}$ is the water saturation of the base model for each grid block.

\subsection{Production strategy optimization}

In this step, the production strategy for each RM is optimized for the time of data acquisition and processing. This enables the quantification of the economic impact of the $4 \mathrm{D}$ seismic data acquisition since these data identify the true representative model, and so the respective strategy should be implemented. The optimization aims to maximize the NPV.

This work uses a field model with a pre-developed strategy and 4 years of production history (i.e. the field is in the management phase), we consider the following variables in the optimization process: production and injection rates, optimal time to shut-in producers and injectors, implementation of sidetracks in existing wells and allocation of new wells. 


\subsection{Chance of Success (CoS) analysis}

We estimate the EVoI using the results obtained in the previous step. The probability of the EVoI must be high enough to cover the cost of data acquisition.

The first analysis considers perfect information. We compare the traditional EVoI calculation with the CoS analysis. The EVoI gives an average value for the information value and is calculated as the difference between the EMV of the project with information and the EMV without information (Eq. (5)). The EMV is the sum of the NPV of each scenario, weighted by its respective probability of occurrence.

$$
\mathrm{EVoI}=\mathrm{EMV}_{\text {with information }}-\mathrm{EMV}_{\text {without information }}
$$

For the CoS analysis, we consider the cumulative probability curve of the $\triangle \mathrm{NPV}$ for each RM. The $\triangle \mathrm{NPV}$ is the difference between the NPV with information $\left(\mathrm{NPV}_{\mathrm{wi}}\right)$ and the NPV without information $\left(\mathrm{NPV}_{\text {woi }}\right)$ (Eq. (6)) for each RM. NPV ${ }_{\text {woi }}$ refers to the economic return of the production strategy of each RM chosen if $4 \mathrm{D}$ seismic is not acquired, while $\mathrm{NPV}_{\mathrm{wi}}$ refers to the economic return of the production strategies optimized for each RM.

$$
\Delta \mathrm{NPV}=\mathrm{NPV}_{\mathrm{wi}}-\mathrm{NPV}_{\text {woi }}
$$

Tables 1 and 2 exemplify the $\triangle$ NPV calculation, as well as the difference between EVoI and $\triangle \mathrm{NPV}$. The number of the strategy in Table 1 refers to the number of the RM it was optimized for. For instance, S1 is the strategy optimized for RM1. This strategy is simulated for all RMs, so that the EMV of each strategy can be calculated. To simplify this example, we consider the RMs having the same probability of occurrence prior to information acquisition.

Note that, in this example, S3 presents the highest EMV $\left(\mathrm{EMV}_{\text {without }}\right.$ information $=$ USD 3092 million $)$. Thus, this strategy would be the chosen if we do not acquire information, and the $\triangle \mathrm{NPV}$ is calculated as the difference between the NPV of the optimized strategy (with information) and the NPV of strategy S3 applied to each RM (without information).

The EMV with information is the average NPV of the optimized strategies $\left(\mathrm{EMV}_{\text {with }}\right.$ information $=(3022+$ $3172+3204) / 3=$ USD 3133 Million). The EVoI, in this example is $(3133-3092)=$ USD 41 million.

Figure 2 shows the CoS analysis for this example. The economic chance of success depends on the cost of the information acquisition. Suppose that a seismic cost is USD 30 million, thus the chance of success is around $60 \%$ (chance of the outputs be higher than this value).

Then, we verify the EVoI when its reliability decreases (imperfect information). To deal with imperfect information, we update the probabilities of occurrence of each RM based on the Bayesian theorem (Clemen, 1996; Santos et al., 2017) shown in equations (7) and (8). This updating procedure is dependent on the level of reliability. A reliability of $100 \%$ reflects perfect information, and as the reliability decreases, the $\mathrm{EVOI}$ information decreases.

$$
P_{\mathrm{u} i}=\frac{P_{\mathrm{r} i} \times P_{\mathrm{c} i}}{P_{\mathrm{P}}}
$$

Table 1. Example of NPV for three RMs (RM1 to RM3, equiprobable prior to information acquisition) simulated for all production strategies (S1-S3) and respective EMV. S3 is selected as the best strategy without further information.

\begin{tabular}{lcccc}
\hline & & \multicolumn{3}{c}{ Strategy } \\
\cline { 3 - 5 } & & S1 & S2 & S3 \\
\hline NPV (millions USD) & RM1 & 3022 & 2984 & 2930 \\
& RM2 & 3059 & 3172 & 3142 \\
& RM3 & 2983 & 3030 & 3204 \\
EMV $\left(10^{6}\right.$ USD) & & 3021 & 3062 & 3092 \\
\hline
\end{tabular}

Table 2. Example of NPV without information $\left(\mathrm{NPV}_{\text {woi }}\right), \mathrm{NPV}$ with information $\left(\mathrm{NPV}_{\text {wi }}\right)$ and $\triangle \mathrm{NPV}$ for the three RMs.

\begin{tabular}{lcccc}
\hline & & & $\begin{array}{c}\text { Prob. of } \\
\text { occurrence } \\
\text { RM }\end{array}$ \\
$\begin{array}{cccc}\mathrm{NPV}_{\text {woi }} \\
\left(10^{6} \text { USD }\right)\end{array}$ & $\begin{array}{c}\mathrm{NPV}_{\text {wi }} \\
\left(10^{6} \text { USD }\right)\end{array}$ & $\begin{array}{c}\Delta \mathrm{NPV} \\
\left(10^{6} \text { USD }\right)\end{array}$ & $\begin{array}{c}\text { (prior to inform. } \\
\text { acquisition })\end{array}$ \\
\hline 1 & 2930 & 3022 & 92 & 0.333 \\
2 & 3142 & 3172 & 30 & 0.333 \\
3 & 3204 & 3204 & 0 & 0.333 \\
\hline
\end{tabular}

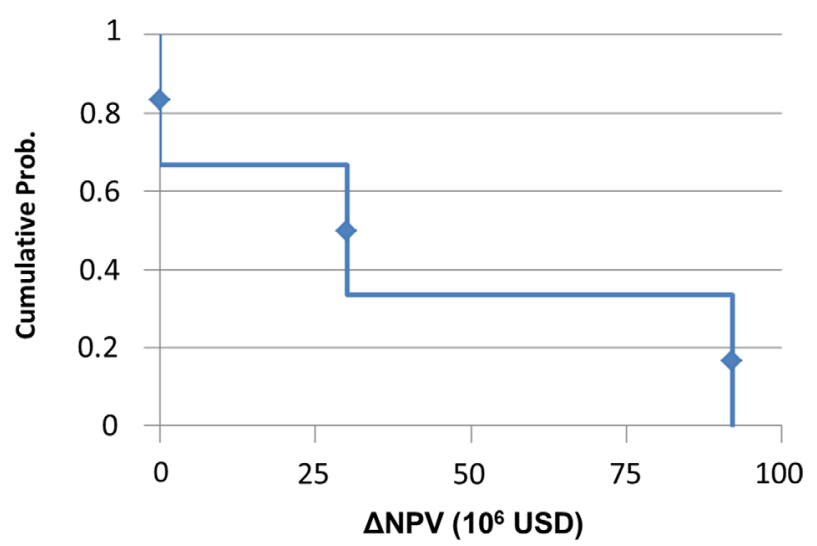

Fig. 2. Example of $\mathrm{CoS}$ analysis $-\Delta \mathrm{NPV} \times$ cumulative probability.

$$
P_{\mathrm{P}}=\sum_{i=1}^{n}\left[P_{\mathrm{r} i} \times P_{\mathrm{c} i}\right]
$$

where $P_{\mathrm{u}}$ is updated probability, $P_{\mathrm{r}}$ is reliability probability, $P_{\mathrm{c}}$ is the current probability and $P_{\mathrm{P}}$ is predicted probability, $i$ is the index or number of the RM, and $n$ is the total number of RM.

That is, $P_{\mathrm{P}}$ is the probability of the seismic data to predict which RM is the closest to the true reservoir model. 


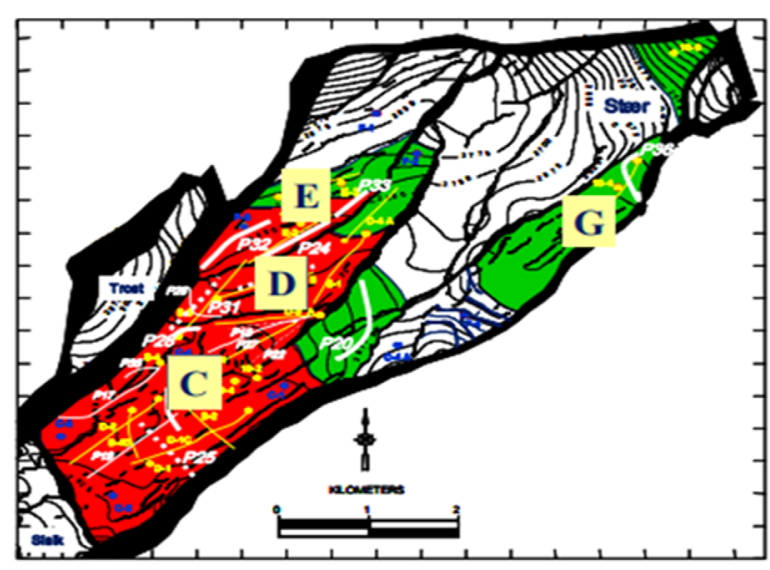

(a)

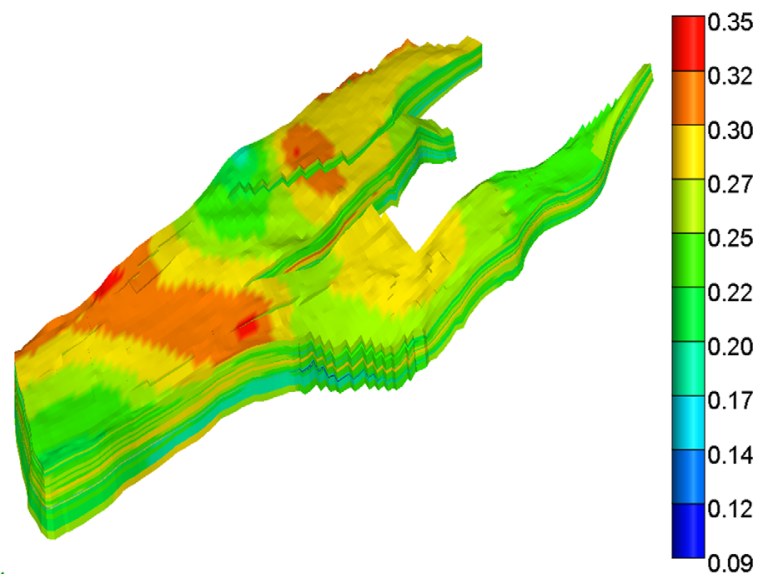

(b)

Fig. 3. (a) Norne segments (Lind, 2004) and (b) 3D view of porosity map for the simulation model.

Table 3. Economic parameters

\begin{tabular}{lcc}
\hline Market values & Discount Rate $(\%)$ & 10 \\
& Oil Price (USD $/ \mathrm{bbl})$ & 25 \\
Costs & Royalties (\%) & 10 \\
& Oil Production (USD $/ \mathrm{bbl})$ & 3.2 \\
& Water Production (USD $/ \mathrm{bbl})$ & 1.3 \\
Investment & Water Injection (USD $/ \mathrm{bbl})$ & 1.3 \\
& Investment in drilling a new horizontal well from subsea surface & 4 \\
& to completion zone $\left(10^{6} \mathrm{USD} / \mathrm{m}\right)$ & 20000 \\
& Horizontal well's investment on drilling a completion & 6 \\
\hline
\end{tabular}

The purpose of $P_{\mathrm{u}}$ is to answer the following question: if the seismic data indicate a specific RM to be the closest to the true reservoir model, what is the probability of this information to be correct (i.e. is the indicated RM truly the closest to the real reservoir model)? Finally, $P_{\mathrm{Ci}}$ is the initial probability, calculated as shown in the previous subsections.

\subsection{Decision-maker evaluation}

Based on the results from previous analyses, the decision maker can end the process (already deciding whether the information must be acquired) or re-evaluate by re-starting the process with the following possibilities: (1) improving the accuracy of analyses by choosing more RMs, (2) evaluating a different acquisition period, or (3) improving the production strategy optimization process.

\section{Application}

This study is applied to the Norne benchmark case. The Norne field is located in the Norwegian continental shelf (200 km west of the mid-Norway coast), extending for $10 \mathrm{~km}, 2 \mathrm{~km}$ wide, and at a water depth of $380 \mathrm{~m}$ (Adlam,
1995). The Norne field comprises two separate oil compartments, the Norne Main structure (Norne C, D, and E segments) and the Northeast Segment (Norne G-Segment) (Fig. 3a). It also consists of five formations, from top to base: Garn, Not, Ile, Tofte, and Tilje (Lind, 2004).

The simulation model is a corner-point grid with $46 \times 112 \times 22$ blocks (44 431 active cells). Figure 3 b shows a $3 \mathrm{D}$ view of a porosity map of the simulation model. This case has four years of production data (from 1997 until 2001), with a production strategy comprising 12 producers and 8 injectors.

\subsection{Economic parameters}

Table 3 shows the economic parameters for the optimization process. Since this is the Norne 2001 case, we considered the optimization for that time, and hence these were the values in force in 2001 .

\section{Results}

\subsection{Risk analysis and selection of representative models}

The uncertainties considered in this work were: rock compressibility, oil-water contact, gas-oil contact, horizontal 


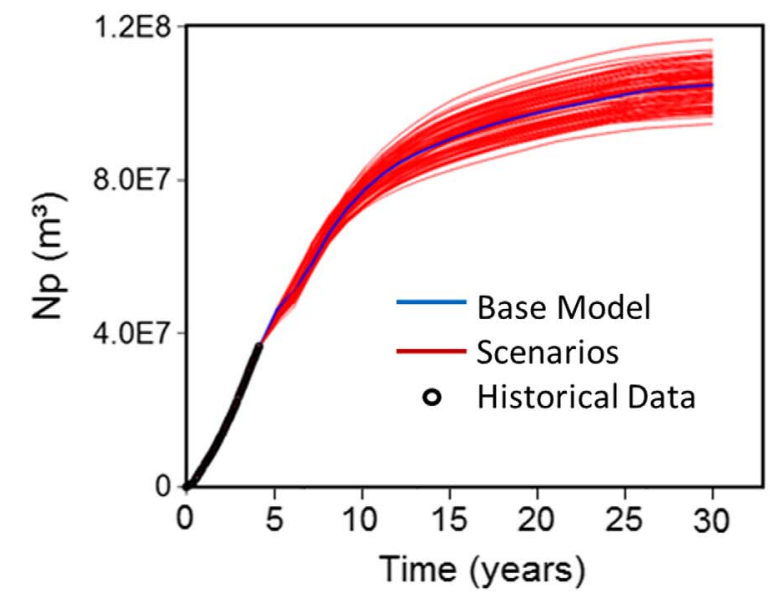

(a)

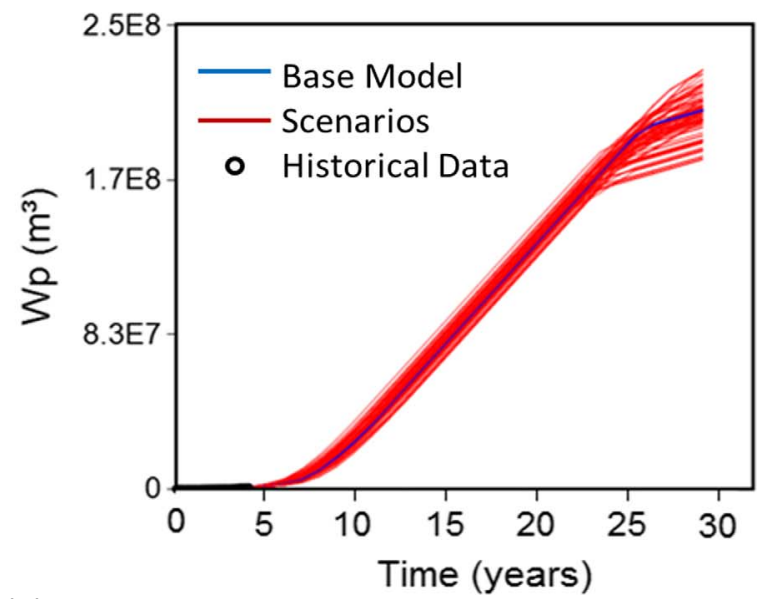

(b)

Fig. 4. Cumulative (a) oil and (b) water production for all scenarios.

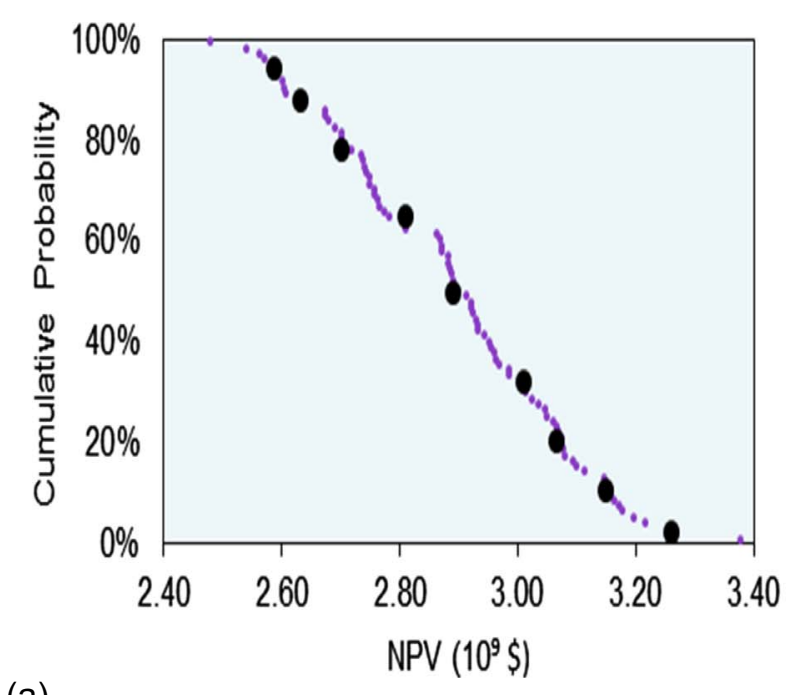

(a)

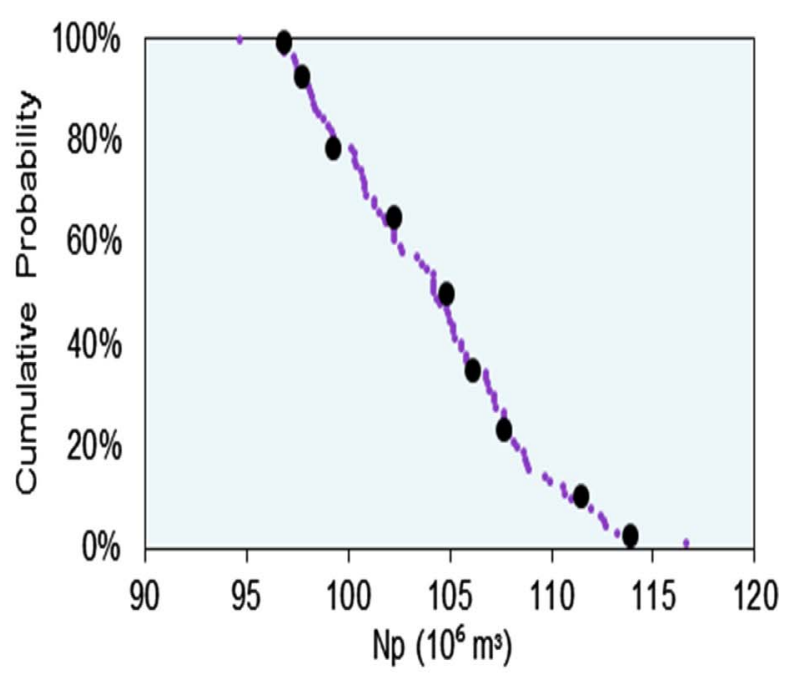

(b)

Fig. 5. Risk curves for (a) NPV and (b) Np. Purple dots represent all scenarios; black dots, the RMs.

and vertical permeability multipliers, porosity multipliers, relative permeability tables, and fault transmissibility. Combining all these uncertainties, 2000 models were generated and a history matching process was performed, filtering 89 models which honored production data. Figure 4 shows the cumulative oil and water production for all scenarios.

We selected nine representative models based on risk curves and cross-plots for the following indicators: NPV, $\mathrm{Np}, \mathrm{Wp}$, and RF. Figure 5 shows the risk curves for NPV and Np, while Figure 6 exemplifies cross-plots analyses. In these graphs, each point represents a simulation model; the purple dots represent all scenarios, while the black dots are the selected RMs. Note that the RMs represent the variability of the uncertain outputs.

Table 4 shows the NPV, cumulative oil and water production, and the probability of occurrence for each RM (calculated using Eqs. (1) and (2)).

\subsection{Acquisition period estimation}

Figure 7 shows the curves of water saturation errors, the sum of the difference of water saturation over every grid cell. There are many scenarios with fluid distributions very different from the base model $\left(\mathrm{S}_{\mathrm{w}}\right.$ error higher than $50 \%$ ) from the beginning of the analysis (year 4 ). Note that the first 4 years relate to past production of the production strategy already implemented, thus our analysis starts at this point.

Figure 8 shows the histograms of production time for a normalized water saturation error of 60\% (Fig. 8a) and 50\% (Fig. 8b), confirming the high level of differences in water distribution between models.

To estimate the best time to acquire 4D seismic data, we also consider the water breakthrough. If the seismic data are acquired before breakthrough, the water flow path can be identified and so the well control optimized to 

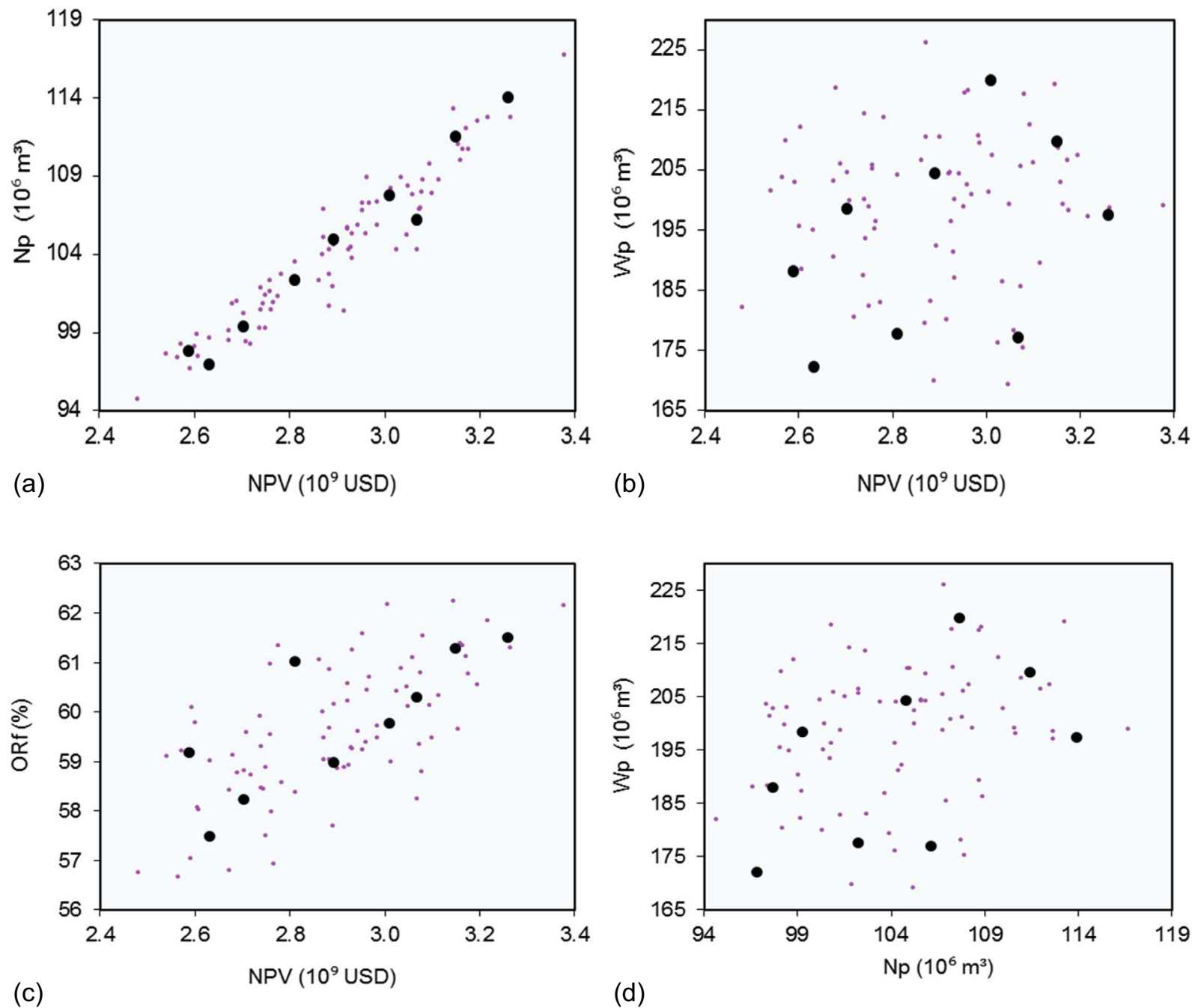

(d)

Fig. 6. Cross-plots: (a) NPV $\times \mathrm{Np}$, (b) NPV $\times \mathrm{Wp},(\mathrm{c}) \mathrm{NPV} \times \mathrm{RF}$, and $(\mathrm{d}) \mathrm{Np} \times \mathrm{Wp}$. Purple dots represent all scenarios; black dots, the RMs.

Table 4. NPV, cumulative oil and water production, and the probability of occurrence of each RM.

\begin{tabular}{lcccc}
\hline & $\begin{array}{c}\text { NPV } \\
\text { RM }\end{array}$ & $\begin{array}{c}\mathrm{Np} \\
\left(10^{6} \text { USD }\right)\end{array}$ & $\begin{array}{c}\text { Wp } \\
\left(10^{6} \mathrm{~m}^{3}\right)\end{array}$ & $\begin{array}{c}\left.\text { (10 } \mathrm{m}^{3}\right) \\
\text { Prob. of occurrence }\end{array}$ \\
\hline 1 & 2868 & 97.7 & 187.9 & 0.10 \\
3 & 3071 & 96.8 & 171.9 & 0.04 \\
4 & 3003 & 99.3 & 198.4 & 0.19 \\
5 & 3099 & 102.3 & 177.5 & 0.07 \\
6 & 3423 & 104.8 & 204.2 & 0.23 \\
7 & 3382 & 107.7 & 219.6 & 0.09 \\
8 & 3476 & 106.1 & 177.0 & 0.11 \\
9 & 3561 & 111.4 & 209.4 & 0.12 \\
\hline
\end{tabular}

improve project economics. Figure 9 shows the number of wells (considering all scenarios) which reached the breakthrough for each production time (Fig. 9a) and the percentage of the number of wells which reached the breakthrough for each production time (Fig. 9b). Note that nearly $50 \%$ of the wells reached breakthrough in the first year of the analysis (year 4).

Considering the water saturation error curves and the breakthrough time, we concluded that the best acquisition period is at the beginning of the management phase, i.e., 4 years after the start of production.

\subsection{Production strategy optimization}

After estimating the best time for $4 \mathrm{D}$ seismic data acquisition, we then optimize the production strategy. As this case is in the management phase (i.e., the production strategy is already implemented), there is little flexibility for changes. The variables we considered are: production and injection rates, optimal shut-in time of producers and injectors, implementation of sidetracks in existing wells, and allocation of new wells. 

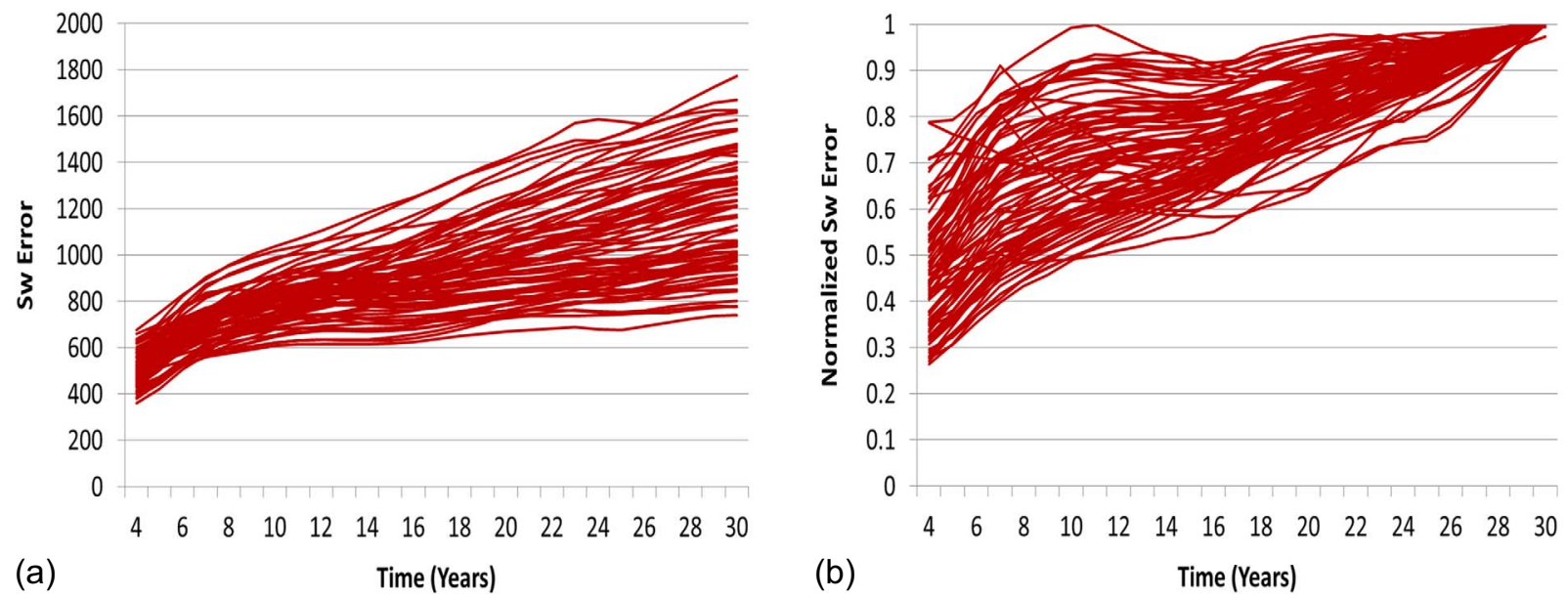

Fig. 7. (a) Water saturation error curves and (b) normalized water saturation error curves.
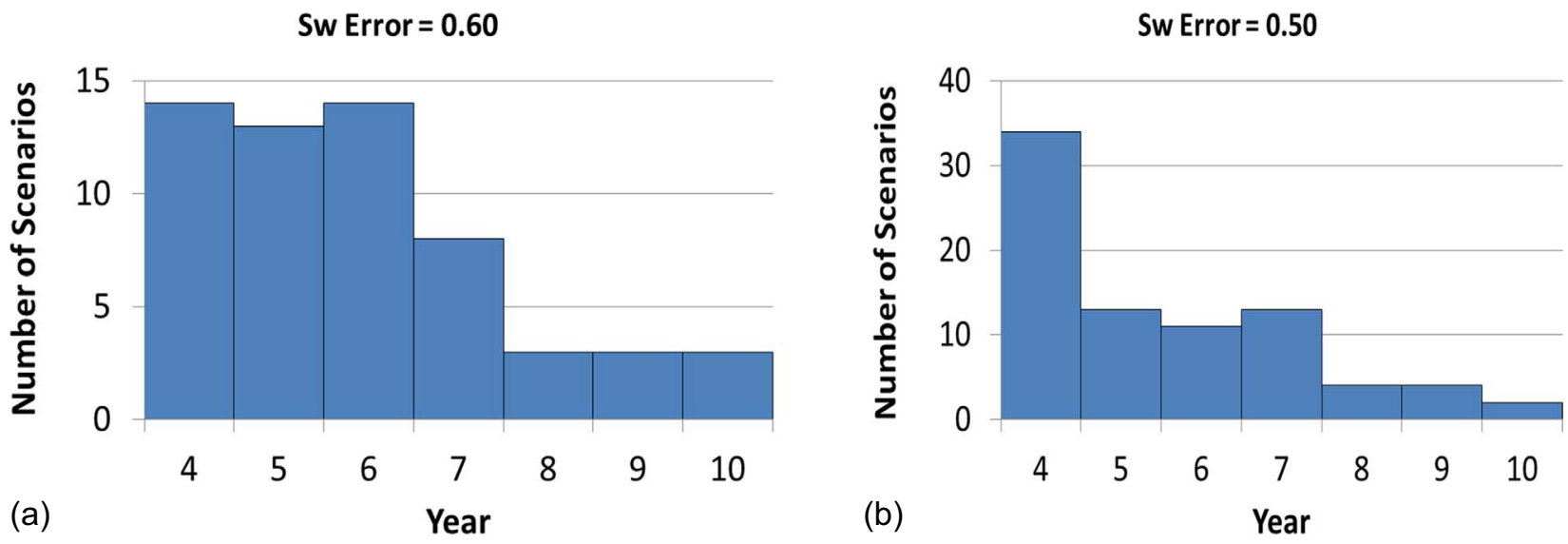

Fig. 8. Histograms - number of scenarios that reached an Sw error of (a) 0.60 and (b) 0.50 in each year of production.
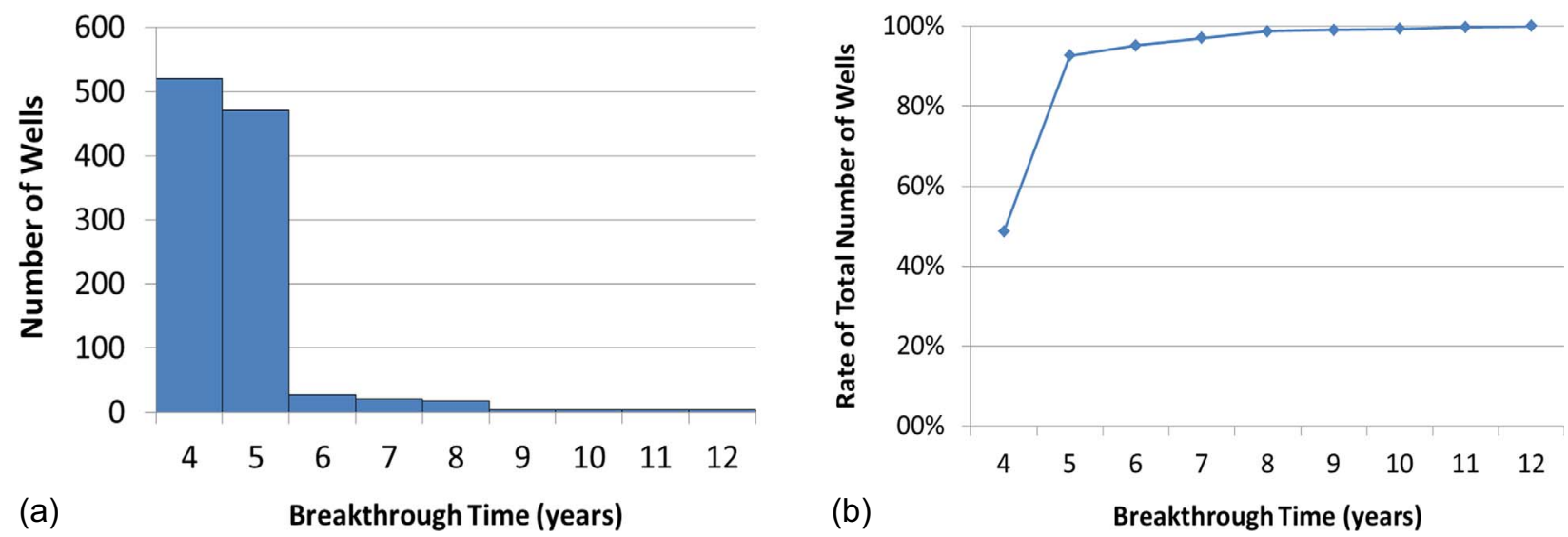

Fig. 9. (a) Histogram of number of wells (considering all scenarios) according to time of breakthrough (years), and (b) rate of total number of wells which reached breakthrough in each year of production.

The $\mathrm{NPV}_{\text {woi }}$ is the economic return for the selected strategy without information acquisition (i.e. the strategy that maximizes EMV) applied to each RM. The economic return after each RM is optimized is $\mathrm{NPV}_{\mathrm{wi}}$. Figure 10 shows the difference between $\mathrm{NPV}_{\text {wi }}$ and $\mathrm{NPV}_{\text {woi }}$. Table 5 shows the results for $\triangle \mathrm{NPV}$ calculation. As $\mathrm{S} 3$ is the 


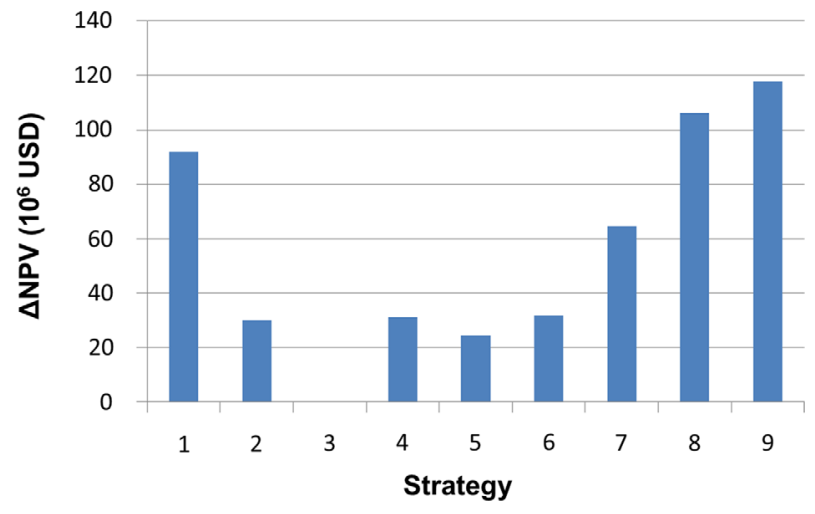

Fig. 10. $\triangle \mathrm{NPV}$ for each strategy.

strategy that maximizes EMV (Tab. 6) and, hence, it would be chosen if no information is acquired, the $\triangle \mathrm{NPV}$ of this strategy is 0 .

\subsection{Chance of Success (CoS) analysis}

\subsubsection{Perfect information analysis}

First, we considered perfect information and calculated the $\mathrm{EVoI}$ using the traditional decision tree, for comparison with the chance of success methodology.

Figure 11 shows the decision tree used to calculate the EVoI. The green squares are decision nodes, the brown circles are chance nodes. The branch labeled "Do not acquire 4DS" represents the possible outcomes from the decision not to acquire information. We simulated the set of production strategies (previously optimized deterministically for each RM) in all possible RMs. We named the strategies according to the RM they were optimized for. Thus, $\mathrm{S} 1$ is the strategy optimized for RM1, S2 is the strategy optimized for RM2, and so on. Then, we calculated the EMV of each strategy. If seismic data is not acquired, we chose the production strategy S3, which maximized EMV (Tab. 6).

The chance node labeled "Acquire 4DS" is in a compact form, since we treated the information as perfect. Thus, as we expect seismic data to provide enough information to identify the closest-to-reality RM, the EMV of the 4DS project is the $\mathrm{NPV}_{\mathrm{wi}}$ of each RM multiplied by its probability of occurrence.

The EVoI - the difference between the EMV when seismic data are acquired and are not acquired - reached the value of USD 47 million.

Being based on a single value, the EVoI cannot express the variability of the increase in the NPV caused by reservoir uncertainties. In the estimation of the chance of success of the $4 \mathrm{DS}$ project, we consider the cumulative probability curve of $\triangle \mathrm{NPV}$ for each RM (Fig. 12). Moreover, the chance of success also depends on the cost of information acquisition, i.e. the increased economic return $(\Delta \mathrm{NPV})$ must be higher than the cost to acquire information. In this study, for a chance of success higher than $50 \%$, the seismic data must cost less than USD 32 Million.
Table 5. Net Present Value without information $\left(\mathrm{NPV}_{\text {woi }}\right)$, Net Present Value with information $\left(\mathrm{NPV}_{\mathrm{wi}}\right)$, $\triangle \mathrm{NPV}$ and probability of occurrence (Prob.) for each strategy.

\begin{tabular}{lcccc}
\hline $\begin{array}{c}\text { RP } \\
\text { RM }\end{array}$ & $\begin{array}{c}\left.\text { NPVi }^{6} \text { USD }\right) \\
\left(10^{6}\right.\end{array}$ & $\begin{array}{c}\Delta \text { NPV } \\
\left(10^{6} \text { USD }\right)\end{array}$ & $\left(10^{6}\right.$ USD $)$ & Prob. \\
\hline 1 & 2930 & 3022 & 92 & 0.10 \\
2 & 3142 & 3172 & 30 & 0.04 \\
3 & 3204 & 3204 & 0 & 0.19 \\
4 & 3145 & 3176 & 31 & 0.07 \\
5 & 3399 & 3423 & 24 & 0.23 \\
6 & 3452 & 3483 & 32 & 0.09 \\
7 & 3430 & 3495 & 65 & 0.11 \\
8 & 3564 & 3670 & 106 & 0.12 \\
9 & 3626 & 3744 & 118 & 0.04 \\
\hline
\end{tabular}

Note the difference between the response of EVoI and CoS: while the former estimated an average economic gain of USD 47 Million, the latter estimated a $45 \%$ chance of the 4DS project yielding a higher return than that (Fig. 12). As these analyses assume perfect information, they provide an upper limit for value information estimate.

Ferreira et al. (2015) showed that the number of selected RMs impacts the analysis. Higher number of RMs leads to more accurate results, but at a certain point the results stabilize. However, choosing many RMs would be too much time consuming, hence it is necessary to balance the accuracy of the results and the time consumption.

In this sense, we performed a sensitivity analysis on the number of RMs (Fig. 13). Using only 3 RMs, the results are very different from the previously obtained. However, with $6 \mathrm{RMs}$, the results are very similar to the ones obtained with 9 RMs.

\subsubsection{Imperfect information analysis}

As information is usually imperfect, some unreliability is expected. In this case, there is a probability that incorrect information could be provided, diminishing the economic return.

Table 7 shows an example of $P_{\mathrm{r}}$ (reliability probability) for an information reliability of 0.9 . That is, if the true model is RM1, there is a probability of $90 \%$ of the seismic data predicting RM1 to be the true model. The other $10 \%$ is divided between the other RMs, weighted by their current probability of occurrence. The same applies to the other RMs.

Table 8 shows the values of $P_{\mathrm{p}}$ (predicting probabilities), and Table 9 shows an example of $P_{\mathrm{u}}$ (updated probabilities) values, both for an information reliability of 0.9. In this example, if the seismic data predicts RM1 to be the true model, then there is a probability of $89.4 \%$ of RM1 being the true model.

Figure 14 exemplifies a decision tree to calculate EVoI considering a reliability of 0.9 . The example presents only the branch "Acquire 4DS" since the branch to calculate 


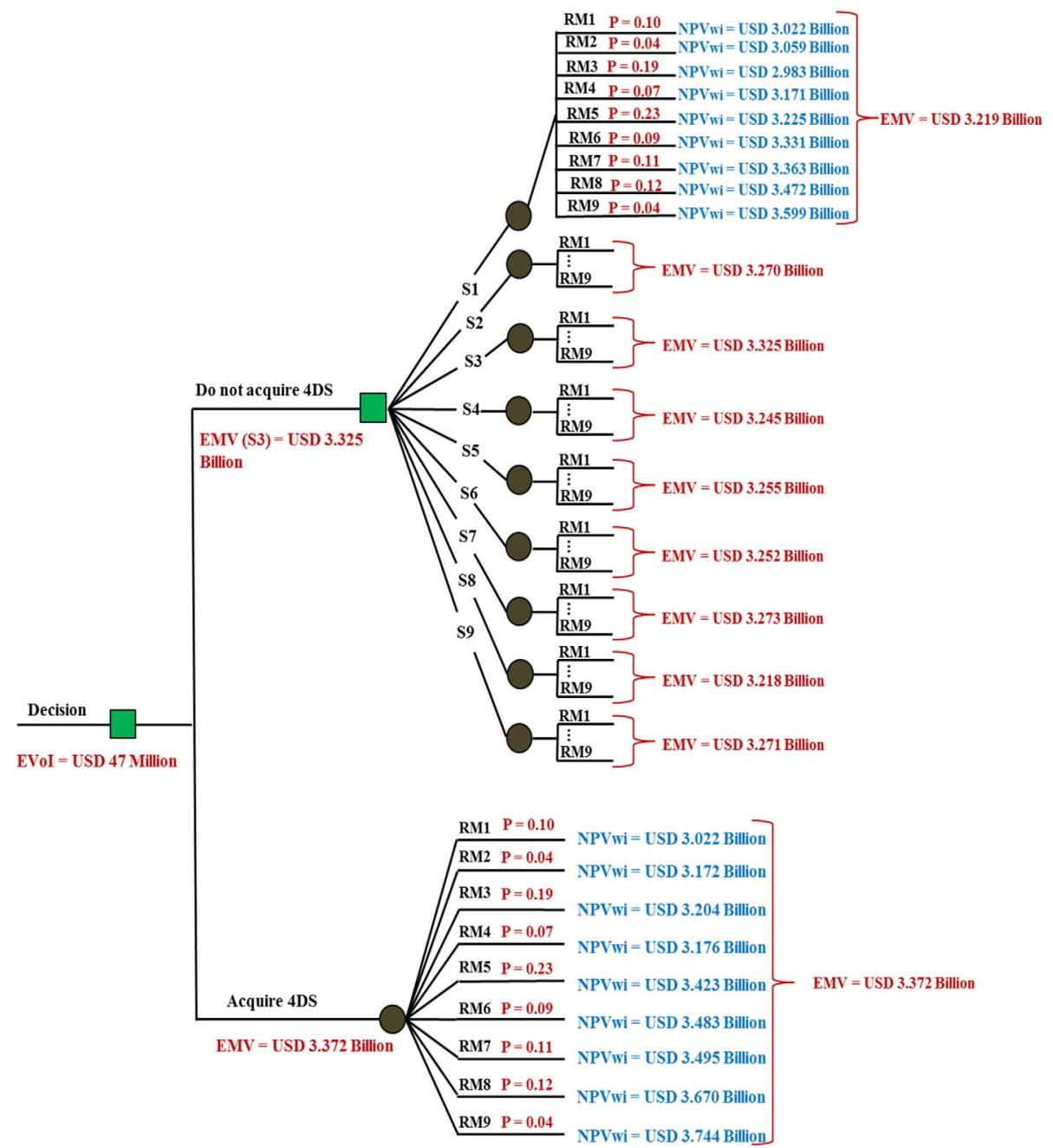

Fig. 11. Compact decision tree for the calculation of the EVoI.

Table 6. NPV of each RM (RM1 to RM9) simulated for all production strategies (S1-S9) and respective EMV. The bold values represent the $\mathrm{NPV}_{\mathrm{wi}}$ of each strategy. The bold value in EMV line represents the maximum EMV among the strategies.

\begin{tabular}{lllllcccccc}
\hline & & \multicolumn{1}{c}{ Strategy } \\
\cline { 2 - 10 } & & S1 & S2 & S3 & S4 & S5 & S6 & S7 & S8 & S9 \\
\hline NPV for each RM $\left(10^{6}\right.$ USD) & RM1 & $\mathbf{3 0 2 2}$ & 2984 & 2930 & 2900 & 2868 & 2900 & 2859 & 2859 & 2968 \\
& RM2 & 3059 & $\mathbf{3 1 7 2}$ & 3142 & 3072 & 3071 & 3103 & 3072 & 3003 & 3091 \\
& RM3 & 2983 & 3030 & $\mathbf{3 2 0 4}$ & 3046 & 3003 & 3073 & 3077 & 2992 & 2988 \\
& RM4 & 3171 & 3085 & 3145 & $\mathbf{3 1 7 6}$ & 3099 & 3121 & 3126 & 3054 & 3167 \\
& RM5 & 3225 & 3323 & 3399 & 3315 & $\mathbf{3 4 2 3}$ & 3275 & 3314 & 3266 & 3347 \\
& RM6 & 3331 & 3447 & 3452 & 3348 & 3382 & $\mathbf{3 4 8 3}$ & 3417 & 3257 & 3338 \\
& RM7 & 3363 & 3419 & 3430 & 3344 & 3376 & 3369 & $\mathbf{3 4 9 5}$ & 3341 & 3418 \\
& RM8 & 3472 & 3516 & 3564 & 3522 & 3481 & 3509 & 3548 & $\mathbf{3 6 7 0}$ & 3577 \\
EMV $\left(10^{6}\right.$ USD) & RM9 & 3599 & 3641 & 3626 & 3567 & 3561 & 3567 & 3645 & 3558 & $\mathbf{3 7 4 4}$ \\
& & 3219 & 3270 & $\mathbf{3 3 2 5}$ & 3245 & 3255 & 3252 & 3273 & 3218 & 3271 \\
\hline
\end{tabular}




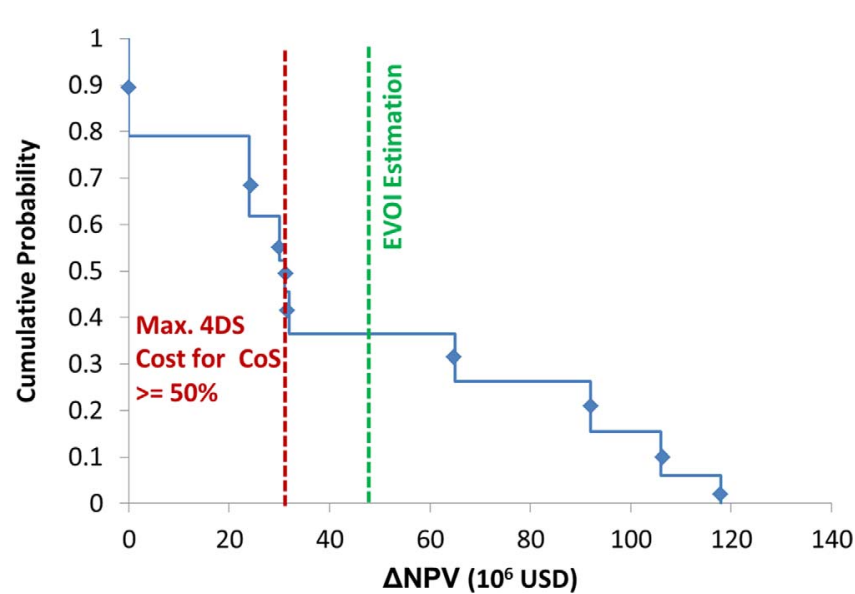

Fig. 12. CoS evaluation for perfect information: cumulative probability curve of the $\triangle \mathrm{NPV}$.

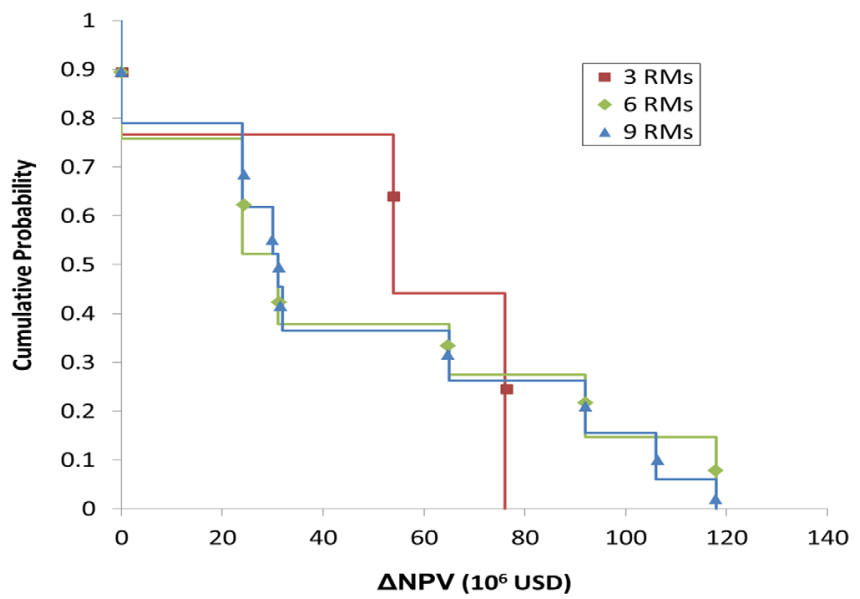

Fig. 13. Sensitivity analysis $-\operatorname{CoS}$ with different number of RMs.

Table 7. Example of $P_{\mathrm{r}}$ (reliability probability) for an information reliability of 0.9.

\begin{tabular}{lllllllllll}
\hline & & \multicolumn{1}{c}{ When the true model is... } \\
\cline { 3 - 11 } ...the seismic data predict & RM1 & $\mathbf{0 . 9 0 0}$ & 0.010 & 0.012 & 0.011 & 0.013 & 0.011 & 0.011 & 0.011 & 0.010 \\
& RM2 & 0.005 & $\mathbf{0 . 9 0 0}$ & 0.005 & 0.005 & 0.006 & 0.005 & 0.005 & 0.005 & 0.005 \\
& RM3 & 0.021 & 0.020 & $\mathbf{0 . 9 0 0}$ & 0.020 & 0.025 & 0.021 & 0.021 & 0.022 & 0.020 \\
RM4 & 0.007 & 0.007 & 0.008 & $\mathbf{0 . 9 0 0}$ & 0.009 & 0.007 & 0.008 & 0.008 & 0.007 \\
& RM5 & 0.026 & 0.024 & 0.029 & 0.025 & $\mathbf{0 . 9 0 0}$ & 0.026 & 0.026 & 0.027 & 0.024 \\
RM6 & 0.010 & 0.009 & 0.011 & 0.010 & 0.012 & $\mathbf{0 . 9 0 0}$ & 0.010 & 0.010 & 0.009 \\
RM7 & 0.012 & 0.012 & 0.014 & 0.012 & 0.014 & 0.012 & $\mathbf{0 . 9 0 0}$ & 0.013 & 0.012 \\
RM8 & 0.014 & 0.013 & 0.015 & 0.013 & 0.016 & 0.013 & 0.014 & $\mathbf{0 . 9 0 0}$ & 0.013 \\
RM9 & 0.005 & 0.005 & 0.005 & 0.005 & 0.006 & 0.005 & 0.005 & 0.005 & $\mathbf{0 . 9 0 0}$ \\
\hline
\end{tabular}

the EMV without information is the same as that shown in Figure 11. Also, we exemplify with one strategy for the first RM, but the branches should be expanded to all nine strategies for all RMs.

We performed a sensitivity analysis on the EMV of the $4 \mathrm{DS}$ project according to the reliability of the information (Fig. 15). When information reliability nears 50\%, it is better not to acquire the information. Similarly, we calculated the EVII, according to each level of reliability, which also showed to be closer to zero as the reliability tends to $50 \%$ (Fig. 16).

The level of reliability also affected the strategy to be chosen when the seismic data indicates an RM to be closest to reality. Table 10 shows the best strategy (with maximum EMV) for each 4DS outcome according to each reliability level. Note that, depending on the reliability of the information, a strategy different to that optimized for the RM itself could be chosen (strategies in bold). For instance, when the seismic data suggests RM4 with a reliability of $70 \%$, strategy S3 is selected (for RM3, the best on average without further information) instead of strategy S4 (optimized for RM4). Most of these changes occur when reliability is
Table 8. Example of $P_{\mathrm{p}}$ values for an information reliability of 0.9 .

\begin{tabular}{lc}
\hline RM & Predicting probability $\left(P_{\mathrm{p}}\right)$ \\
\hline RM1 & 0.101 \\
RM2 & 0.045 \\
RM3 & 0.188 \\
RM4 & 0.067 \\
RM5 & 0.230 \\
RM6 & 0.090 \\
RM7 & 0.112 \\
RM8 & 0.123 \\
RM9 & 0.045 \\
\hline
\end{tabular}

between $70 \%$ and $50 \%$. Thus, highly imperfect information (less than $70 \%$ reliable in our case study) is insufficient to alter the perception of the uncertain reservoir and thus inadequate to change decisions. 
Table 9. Example of updated probabilities $\left(P_{\mathrm{u}}\right)$ for an information reliability of 0.9 .

\begin{tabular}{lllllllllll}
\hline & & \multicolumn{1}{c}{ When the seismic predicts... } \\
\cline { 3 - 11 } & & RM1 & RM2 & RM3 & RM4 & RM5 & RM6 & RM7 & RM8 & RM9 \\
\hline ..the true model is & RM1 & $\mathbf{0 . 8 9 4}$ & 0.011 & 0.011 & 0.011 & 0.011 & 0.011 & 0.011 & 0.011 & 0.011 \\
& RM2 & 0.005 & $\mathbf{0 . 8 8 9}$ & 0.005 & 0.005 & 0.005 & 0.005 & 0.005 & 0.005 & 0.005 \\
& RM3 & 0.023 & 0.023 & $\mathbf{0 . 9 0 5}$ & 0.023 & 0.024 & 0.023 & 0.023 & 0.023 & 0.023 \\
RM4 & 0.007 & 0.007 & 0.007 & $\mathbf{0 . 8 9 1}$ & 0.007 & 0.007 & 0.007 & 0.007 & 0.007 \\
RM5 & 0.030 & 0.030 & 0.031 & 0.030 & $\mathbf{0 . 9 1 2}$ & 0.030 & 0.030 & 0.030 & 0.030 \\
RM6 & 0.010 & 0.010 & 0.010 & 0.010 & 0.010 & $\mathbf{0 . 8 9 3}$ & 0.010 & 0.010 & 0.010 \\
RM7 & 0.012 & 0.012 & 0.013 & 0.012 & 0.013 & 0.012 & $\mathbf{0 . 8 9 6}$ & 0.012 & 0.012 \\
RM8 & 0.014 & 0.014 & 0.014 & 0.014 & 0.014 & 0.014 & 0.014 & $\mathbf{0 . 8 9 7}$ & 0.014 \\
RM9 & 0.005 & 0.005 & 0.005 & 0.005 & 0.005 & 0.005 & 0.005 & 0.005 & $\mathbf{0 . 8 8 9}$ \\
\hline
\end{tabular}

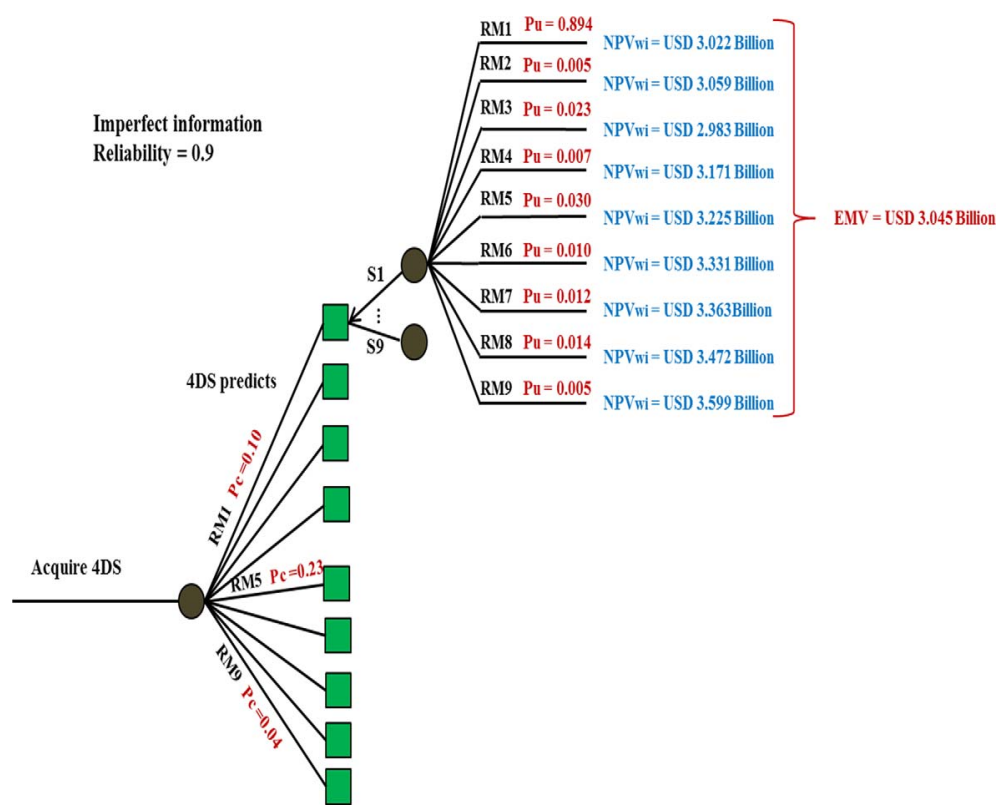

Fig. 14. Simplified decision tree for EVoI calculation considering imperfect information with a reliability of 0.9 .

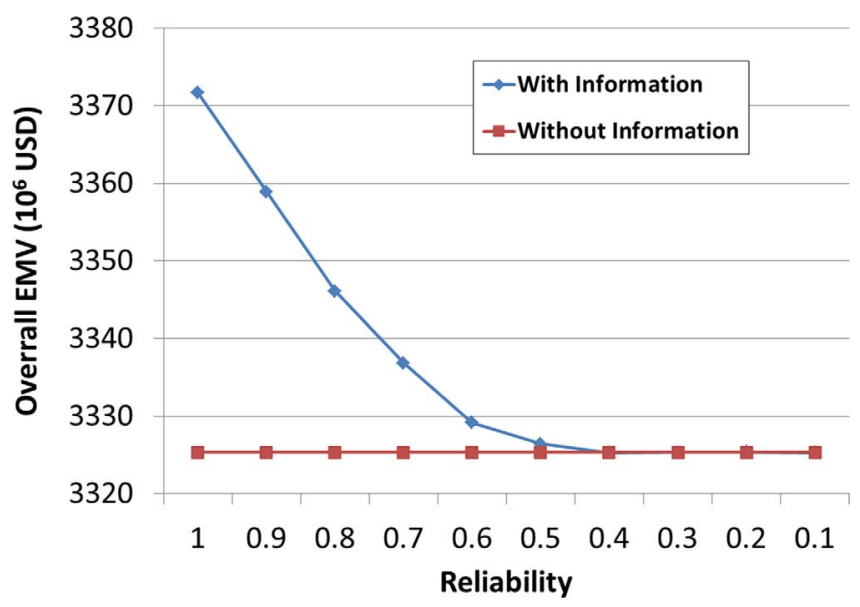

Fig. 15. Variation of the EMV of the 4DS project with information reliability.

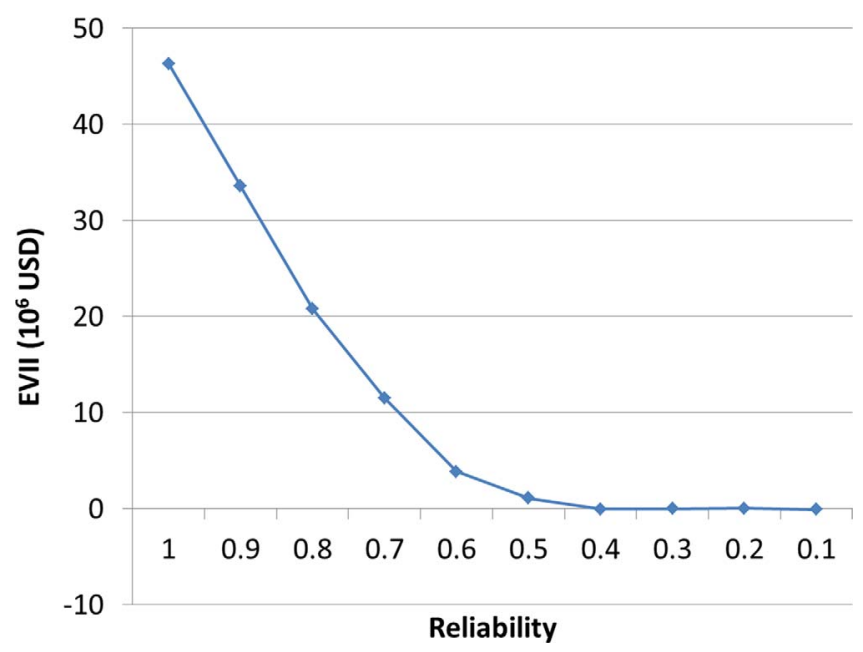

Fig. 16. Variation of EVII according to each level of reliability. 
Table 10. Best strategy (maximum EMV) for each 4DS outcome (represented by the representative models) according to each level of information reliability. Strategies in bold represent changes in the decision when compared to the case with perfect information.

\begin{tabular}{llllllllllll}
\hline & & \multicolumn{10}{c}{ Best strategy when reliability is... } \\
\cline { 3 - 10 } & & 1 & 0.9 & 0.8 & 0.7 & 0.6 & 0.5 & 0.4 & 0.3 & 0.2 & 0.1 \\
\hline 4DS predicts... & RM1 & S1 & S1 & S1 & S1 & S2 & S3 & S3 & S3 & S3 & S3 \\
& RM2 & S2 & S2 & S2 & S2 & S3 & S3 & S3 & S3 & S3 & S3 \\
& RM3 & S3 & S3 & S3 & S3 & S3 & S3 & S3 & S3 & S3 & S3 \\
& RM4 & S4 & S4 & S4 & S3 & S3 & S3 & S3 & S3 & S3 & S3 \\
& RM5 & S5 & S5 & S5 & S3 & S3 & S3 & S3 & S3 & S3 & S3 \\
& RM6 & S6 & S6 & S6 & S3 & S3 & S3 & S3 & S3 & S3 & S3 \\
& RM7 & S7 & S7 & S7 & S7 & S7 & S3 & S3 & S3 & S3 & S3 \\
& RM8 & S8 & S8 & S8 & S8 & S8 & S3 & S3 & S3 & S3 & S3 \\
& RM9 & S9 & S9 & S9 & S9 & S9 & S9 & S9 & S3 & S3 & S3 \\
\hline
\end{tabular}

\section{Conclusion}

This work presented the practical application of the CoS estimation in a real case, providing decision-makers with a tool to decide whether or not to acquire information (in the case of this work, the information would be provided by $4 \mathrm{D}$ seismic). This is a model-based study, where information identifies the representative model closest to the true reservoir model, and decisions correspond to implementing the production strategy optimized for that model.

While the traditional expected value of information calculation provides only an average value, the chance of success considers the variability in the economic return due to reservoir uncertainties. We assessed perfect information to obtain the upper limit for the VoI.

We also showed that, when information is imperfect, the decision of which production strategy to implement changes with information reliability. Moreover, when the reliability reaches a level of around $50 \%$, the information no longer has value, since the economic return, in this case, is similar to that of the case without information. Furthermore, highly imperfect information (less than $70 \%$ reliable in our case study) is insufficient to change the perception of the uncertain reservoir and consequently decisions.

Acknowledgments. This work was carried out in association with the ongoing Project registered as BG-07 "Reduction of uncertainties through the incorporation of $4 \mathrm{D}$ seismic data in the modeling of the reservoir" (UNICAMP/Shell Brazil/ANP) funded by Shell Brazil under the ANP R\&D levy as "Investment Commitment to Research and Development". The authors also thank Energi Simulation, CEPETRO, UNICAMP, DE-FEM for supporting this work and CMG for software licenses.

\section{References}

Abellan A., Noetinger B. (2010) Optimizing subsurface field data acquisition using information theory, Math. Geosci. 42, 603-630. https://doi.org/10.1007/s11004-010-9285-6.
Adlam J. (1995) The Norne Field Development Overview. Offshore Technology Conference, Houston, 1-4 May, OTC7925-MS. https://doi.org/10.4043/7925-MS

Bailey W.J., Couët B., Prange M. (2011) Forecast optimization and value of information under uncertainty, in: Ma Y.Z., La Pointe P.R. (eds), Uncertainty analysis and reservoir modeling, AAPG Memoir 96, 217-233. doi: 10.1306/ 13301416M963484.

Ballin P.R., Ward G.S., Whorlow C.V., Khan T. (2005) Value of information for a 4-D seismic acquisition project. SPE 94918MS, Annual Technical Conference and Exhibition, Denver, Colorado, USA. https://doi.org/10.2118/94918-MS.

Barros E.G.D., Jansen J.D., van den Hof P.M.J. (2015) Value of information in parameter identification and optimization of hydrocarbon reservoirs, IFAC-Papers OnLine 48, 6, 229-235. https://doi.org/10.1016/j.ifacol.2015.08.036.

Barros E.G.D., van den Hof P.M.J., Jansen J.D. (2016) Value of information in closed-loop reservoir management, Comp. Geosci. 20, 3, 737-749. https://doi.org/10.1007/s10596-0159509.

Begg S., Bratvold R., Campbell J. (2002) The value of flexibility in managing uncertainty in oil and gas investments. SPE 77586-MS, Annual Technical Conference and Exhibition, San Antonio, Texas, USA. https://doi.org/10.2118/77586-MS.

Bratvold R.B., Bickel J.E., Lohne H.P. (2009) Value of information in the oil and gas industry: Past, present and future. SPE 110378-PA, SPE Reserv. Eval. Eng. 12, 04, 630-638. https://doi.org/10.2118/110378-PA.

Chen B., He J., Wen X.H., Chen W., Reynolds A.C. (2017) Uncertainty quantification and value of information assessment using proxies and Markov chain Monte Carlo method for a pilot project, J. Petrol. Sci. Eng. 157, 328-339. https://doi.org/10.1016/j.petrol.2017.07.039.

Clemen R.T. (1996) Making hard decisions: An introduction to decision analysis, Second Edition, Duxbury Press, USA.

Coopersmith E.M., Cunningham P.C. (2002) A practical approach to evaluating the value of information and real option decisions in the upstream petroleum industry. SPE 77582-MS, Annual Technical Conference and Exhibition, San Antonio, Texas, USA. https://doi.org/10.2118/77582-MS.

Costa A.P.A., Schiozer D.J., Moczydlower P., Bedrikovetsky P. (2008) Use of representative models to improve the decision making process of chemical flooding in a mature field. SPE 
115442, SPE Russian Oil \& Gas Technical Conference and Exhibition, Moscow, Russia. https://doi.org/10.2118/115442MS.

Davolio A., Schiozer D.J. (2018) Probabilistic seismic history matching using binary images, J. Geophys. 15, 261-274. https://doi.org/10.1088/1742-2140/aa99f4.

Dunn M.D. (1992) A method to estimate the value of well log information. SPE 24672-MS, Annual Technical Conference and Exhibition, Washington, D.C., USA. https://doi.org/ 10.2118/24672-MS.

Eidsvik J., Mukerji T., Bhattacharjya D. (2015) Value of information in the Earth sciences: Integrating spatial modeling and decision analysis, 1st edn., Cambridge University Press, Cambridge, United Kingdom.

Evensen G. (1994) Sequential data assimilation with a nonlinear quasi-geostrophic model using Monte Carlo methods to forecast error statistics, J. Geophys. 99, C5, 10143-10162. https://doi.org/10.1029/94JC00572.

Ferreira C.J., Schiozer D.J. (2013) Time-lapse seismic and engineering data integration to estimate best time for seismic acquisition data. SPE 164914-MS, EAGE Annual Conference 8 Exhibition Incorporating Europec, London, United Kingdom. https://doi.org/10.2118/164914-MS.

Ferreira C.J., Schiozer D.J. (2014) Methodology to estimate the chance of success of a time-lapse seismic project using reservoir simulation. SPE 170674-MS, Annual Technical Conference and Exhibition, Amsterdam, The Netherlands. https://doi.org/ 10.2118/170674-MS.

Ferreira C.J., Davolio A., Maschio C., Schiozer D.J. (2011) Evaluation of the seismic time_lapse acquisition period in reservoir monitoring. OTC-22 $\overline{7} 40$, Offshore Technology Conference Brasil, Rio de Janeiro, Brazil. https://doi.org/ 10.4043/22740-MS.

Ferreira C.J., Davolio A., Schiozer D.J. (2015) Improving the estimation of the chance of success of a $4 \mathrm{D}$ seismic project based on representative models. SPE 174386-MS, SPE Europec, Madrid, Spain. https://doi.org/10.2118/174386-MS.

Galli A., Armstrong M., Dias M.A.G. (2004) The value of information: A Bayesian real option approach. SPE 90418MS, Annual Technical Conference and Exhibition, Houston, Texas, USA. https://doi.org/10.2118/90418-MS.

Gerhardt J.H., Haldorsen H.H. (1989) On the Value of Information. SPE 19291-MS, Offshore Europe, Aberdeen, United Kingdom. https://doi.org/10.2118/19291-MS.

Grayson, Jr. C.J. (1960) Decisions under uncertainty: Drilling decisions by oil and gas operators, Harvard University Press, Boston, Massachusetts, USA.

He J., Xie J., Sarma P., Wen X.H., Chen W.H., Kamath J. (2016) Proxy-based Work flow for a priori evaluation of dataacquisition programs, SPE J. 21, 4, SPE-173229-PA. https://doi.org/10.2118/173229-PA.

Hong A.J., Bratvold R.B., Thomas P., Hanea R.G. (2018) Value-of-information for model parameter updating through history matching, J. Petrol. Sci. Eng. 165, 253-268. https://doi.org/10.1016/j.petrol.2017.08.028.

Howard R.A. (1966) Information value theory, IEEE T. Syst. Man. Cyb. 2, 1, 22-26, http://dx.doi.org/10.1109/TSSC.1966.300074.

Le Ravalec M., Tillier E., Da Veiga S., Enchéry G., Gervais V. (2012a) Advanced integrated workflows for incorporating both production and $4 \mathrm{D}$ seismic-related data into reservoir models, Oil Gas Sci. Technol. - Rev. IFP Energies nouvelles 67, 2, 207-220. https://doi.org/10.2516/ogst/2011159.

Le Ravalec M., Da Veiga S., Derfoul R., Enchéry G., Gervais V., Roggero F. (2012b) Integrating Data of Different Types and Different Supports into Reservoir Models, Oil Gas Sci. Technol. - Rev. IFP Energies nouvelles 67, 5, 823-839. https://doi.org/10.2516/ogst/2012024.

Lind O. (2004) Annual Reservoir Development Plan - Norne Field, Statoil Internal Report.

Marques M.D., Gaspar A.T., Schiozer D.J. (2013) Use of oil reservoir simulation to estimate value of flexibility. SPE 164878, EAGE Annual Conference \& Exhibition incorporating Europec, London, United Kingdom. https://doi.org/10.2118/ 164878-MS

Meira L.A.A., Coelho G.P., Santos A.A.S., Schiozer D.J. (2016) Selection of representative models for decision analysis under uncertainty, Comput. Geosci. 88, 67-82. https://doi.org/ 10.1016/j.cageo.2015.11.012

Meira L.A.A., Coelho G.P., Silva C.G., Santos A.A.S., Schiozer D.J. (2017) RMFinder 2.0: An improved interactive multicriteria scenario reduction methodology. SPE 185502, SPE Latin America and Caribbean Petroleum Engineering Conference. https://doi.org/10.1016/j.cageo.2015.11.012

Raiffa H. (1968) Decision analysis: Introductory lectures on choices under uncertainty, Addison-Wesley, Reading, Massachusetts, USA.

Roggero F., Lerat O., Ding D.Y., Berthet P., Bordenave C., Lefeuvre F., Perfetti P. (2012) History matching of production and 4D seismic data: Application to the Girassol Field, Offshore Angola, Oil Gas Sci. Technol. - Rev. IFP Energies nouvelles 67, 2, 237-262. https://doi.org/10.2516/ogst/2011148

Santos S.M.G., Gaspar A.T.F.S., Schiozer D.J. (2017) Value of information in reservoir development projects: Technical indicators to prioritize uncertainties and information sources, J. Petrol. Sci. Eng. 157, 1179-1191. https://doi.org/10.1016/ j.petrol.2017.08.028

Sarma P., Chen W.H., Xie J. (2013) Selecting representative models from a large set of models. SPE 163671, SPE Reservoir Simulation Symposium, The Woodlands, Texas, USA. https://doi.org/10.2118/163671-MS.

Schiozer D.J., Ligero E.L., Suslick S.B., Costa A.P.A., Santos J.A.M. (2004) Use of representative models in the integration of risk analysis and production strategy definition, J. Petrol. Sci. Eng. 44, 1-2, 131-141. https://doi.org/10.1016/j.petrol.2004. 02.010

Schlaifer R. (1959) Probability and statistics for business decisions: an introduction to managerial economics under uncertainty, McGraw-Hill Book Company, New York City, USA.

Shirangi M.G., Durlofsky L.J. (2015) Closed-loop field development under uncertainty by use of optimization with sample validation. SPE 173219-PA, SPE J. 20, 5, 908-922. https://doi.org/10.2118/173219-PA

Tillier E., Le Ravalec M., Da Veiga S. (2012) Simultaneous inversion of production data and seismic attributes: application to a synthetic SAGD produced field case, Oil Gas Sci. Technol. - Rev. IFP Energies nouvelles 67, 2, 289-301. https://doi.org/10.2516/ogst/2012004

Waggoner J.R. (2002) Quantifying the Economic Impact of 4D Seismic Projects. SPE 77969-PA, SPE Reserv. Eval. Eng. 5, 02, 111-115. https://doi.org/10.2118/77969-PA 